\title{
Using Wavelet Analysis to Assess the Impact of COVID-19 on Changes in the Price of Basic Energy Resources
}

\author{
Syed Khalid Mustafa ${ }^{1}$, M. Ayaz Ahmad ${ }^{2}$, Valeria Baranova ${ }^{3}$, Zhanna Deineko ${ }^{4}$, Vyacheslav Lyashenko ${ }^{5}$, \\ Atif Abdulwahab A. Oyouni ${ }^{6}$ \\ ${ }^{1}$ Department of Chemistry, Faculty of Science, University of Tabuk, Saudi Arabia, \\ khalid.mustafa938@gmail.com \\ ${ }^{2}$ Department of Physics, Faculty of Science, University of Tabuk, Saudi Arabia, mayaz.alig@ gmail.com \\ ${ }^{3}$ Department of Travel Business and Regional Studies, V. N. Karazin Kharkiv National University, Ukraine, \\ Valeria-baranova@ukr.net \\ ${ }^{4}$ Department of Media Systems and Technology, Kharkiv National University of Radio Electronics, Ukraine, \\ zhanna.deineko@nure.ua \\ ${ }^{5}$ Department of Informatics, Kharkiv National University of Radio Electronics, Ukraine, \\ lyashenko.vyacheslav@gmail.com \\ ${ }^{6}$ Department of Biology, Faculty of Science, University of Tabuk, Tabuk, 71491, Saudi Arabia, \\ a.oyouni@ut.edu.sa
}

\begin{abstract}
To overcome a pandemic, reliable statistics are needed. It is also important to use assess the development and impact of the pandemic. This is important for making effective management decisions. Based on this, the paper analyzes the impact of COVID-19 on changes in the price of basic energy resources. This analysis is based on the ideology of wavelets. We used the method to calculate wavelet coherence estimates. The adequacy of using the ideology of wavelets to obtain appropriate estimates is shown. The results are obtained for real data.
\end{abstract}

Key words: Viruses, Pandemic, COVID-19, Energy Resources, Wavelet Coherence, Price.

\section{INTRODUCTION}

Viruses, epidemics and pandemics are components of human life. These viruses, epidemics and pandemics are considered as sources of various negative phenomena. Among these phenomena can be identified: an increase in the morbidity of the population, an increase in fatal cases, a decrease in productivity, the impact on the economic stability of the development of society [1].

To minimize the impact of such negative phenomena, it is important to know the dynamics of an epidemic or pandemic. It is also important to know the influence of this dynamics on the development of other processes that are being studied. To do this, you must have reliable statistics. A prerequisite for applying the data is the ability to explain the existing relationships between the various parameters that describe the dynamics of the epidemic (pandemic) and other processes under study. Therefore, it is equally important to analyze the data that are available.

Data analysis is an important tool for understanding the development of COVID-19 and its impact on various components of human life. At the same time, COVID-19 flash analysis models are imperfect [2]. This is due to the fact that data on the distribution of COVID-19 are limited, and the epidemiological characteristics are not completely determined.

From the point of view of the stability of the development of society, the production of goods, human life, it is important to know and take into account the dynamics of changes in prices for basic energy resources [3]. Among these main energy resources, oil and natural gas should be highlighted. Then, one of the objectives of the study should be an assessment of the relationship between the development of the COVID-19 pandemic and changes in oil and natural gas prices. It is these issues that this study is dedicated to.

\section{REVIEW OF THE LITERATURE}

Today, there are number of works that consider information on COVID-19 transmission with different mathematical models. In existing works, analysis is presented starting from weekly statistics and ending with a monthly analysis of COVID-19 outbreaks and "fatal" cases.

All these works are aimed at simulating and predicting real COVID-19 outbreak, as well as determining specific numbers of deaths. 
For example, in [4] early dynamics of transmission and control of COVID-19: mathematical modeling studies are presented. The process of modeling COVID-19 transmission of during January 2020 and February 2020 is described. There are used two additional data sets for comparison with model output: daily number of new exported cases from Wuhan (or their absence) and data on new confirmed cases recorded in Wuhan.

In [5], authors focused on considering measures to control COVID-19 transmission at earliest stage - during first 50 days of epidemic. The authors investigated transmission and control of COVID-19 using a dataset of specific cases, methods of epidemic transmission, and medical interventions.

In [6], COVID-19 was simulated to estimate actual number of sick and fatal cases that were not reported during first half of January 2020.

Assessment of COVID-19 infected population extent and dynamics of transmission of epidemic in February 2020 are described in [7]. Based on publicly available and published information, authors evaluated risk of death. According to [7], it is precisely level of population that is key parameter in determining dynamics of epidemic transmission, as well as in predicting COVID-19 transmission paths.

Data on epidemic for March 2020 are presented in [8]. The authors carried out an empirical transmission of delays of epidemic, as well as simulated a generalized model of increase in number of infected people and, as result, using discrete transmission of COVID-19 propagation interval probabilities, estimated outbreak period.

At the same time, another area of research determines the impact of the COVID-19 pandemic on various processes of human life.

The paper [9] analyzes the impact of the COVID-19 pandemic on price changes in financial markets. This allows you to evaluate the financial stability and development of production in various countries.

In [10], [11] the effect of COVID-19 on falling oil prices is investigated. Particular attention is paid to geopolitical risks and the development of the stock market in a pandemic. All this affects the life of a person.

For this analysis, various statistical methods are used, the corresponding models are constructing. These models are based on time series analysis. At the same time, the application of the ideology of wavelets is promising [12], [13]. The use of such an ideology allows us to identify hidden trends, conduct research at different time intervals. Therefore, for the purposes of this study, we will use wavelet analysis methods.

\section{WAVELET COHERENCE AS A WAVELET ANALYSIS TOOL}

The ideology of wavelets allows the analysis of data that is presented in the form of a time series. Such an analysis can be performed for each data series and for the analysis of the mutual dynamics between two data series.

In the first case, we examine development trends for a particular series of data.

In the second case, we can evaluate the dynamics of mutual influence. We can also explore cross-references between the series that are being investigated. For this, a method is used that is based on the estimation of wavelet coherence [12], [13]. All this allows us to do data mining [14]-[16].

To determine the values of wavelet coherence, we consider the values of cross wavelet spectra $W_{x y}(g, q)$ for two data series $g(t)$ and $q(t)$ ( $x$ is the variable that displays the data number in the series under investigation and $y$ is the variable that displays the depth of cross-links for a time series $-t$ ). The general formula has the following form [12], [13], [17], [18]:

$$
R^{2}(g, q)=\frac{\left|D\left(k^{-1} W_{x y}(g, q)\right)\right|}{D\left(k^{-1}\left|W_{x}(g, q)\right|^{2}\right) D\left(k^{-1}\left|W_{y}(g, q)\right|^{2}\right)},
$$

where: $D$ is a smoothing operator, $0 \leq R^{2}(g, q) \leq 1$.

To calculate the values of the wavelet coherence (in accordance with formula 1), we use the Morlet wavelet. If these values tend to zero, then we have a weak correlation. Otherwise, we have a strong correlation [12]. To assess the reliability of the wavelet coherence values, the Monte Carlo method is used [13].

\section{DATA FOR ANALYSIS}

In accordance with the research topic, we consider the following initial data:

- COVID-19 statistics, which reflect the cumulative total of cases diseased (Figure 1). Generalized data from the site: https://www.who.int/emergencies/diseases/novel-coronavirus -2019. These data are presented in the period 18.01.2020-27.06.2020; 


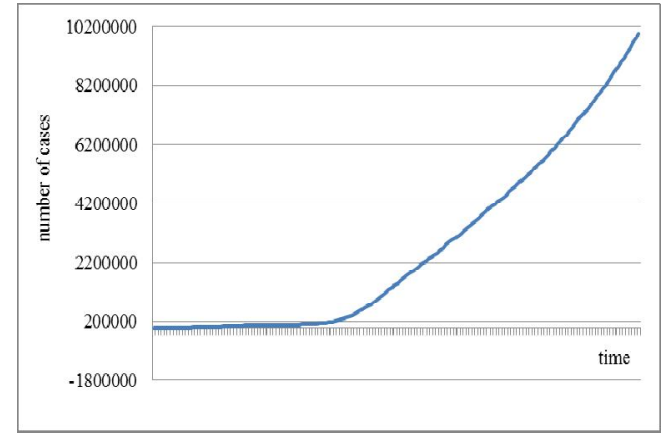

Figure 1: Statistics on COVID-19 (reflect the cumulative total of cases diseased)

- COVID-19 statistics, which reflect the data in the context of each day from the studied interval (Figure 2). Generalized data from the site:

https://www.who.int/emergencies/diseases/novel-coronavirus -2019). These data are presented in the period 18.01.2020-27.06.2020.

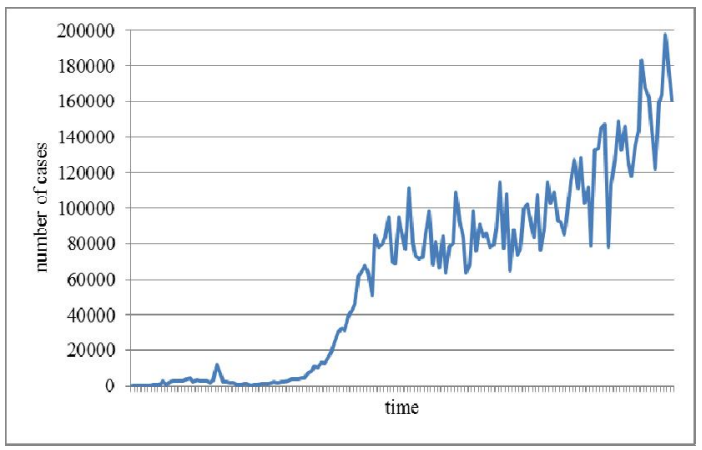

Figure 2: Statistics on COVID-19 (data of cases diseased in the context of each day from the studied interval)

The data in Figure 1 and Figure 2 show the same trends in the number of cases of diseased COVID-19. At the same time, we can observe some details of such dynamics for the data presented in Figure 2. Therefore, these data series can be used for the corresponding analysis.Figure 3 shows the dynamics of prices for BRENT and WTI crude oil (data from https://index.minfin.com.ua/markets/oil/). These data are presented in the period 18.01.2020-27.06.2020.

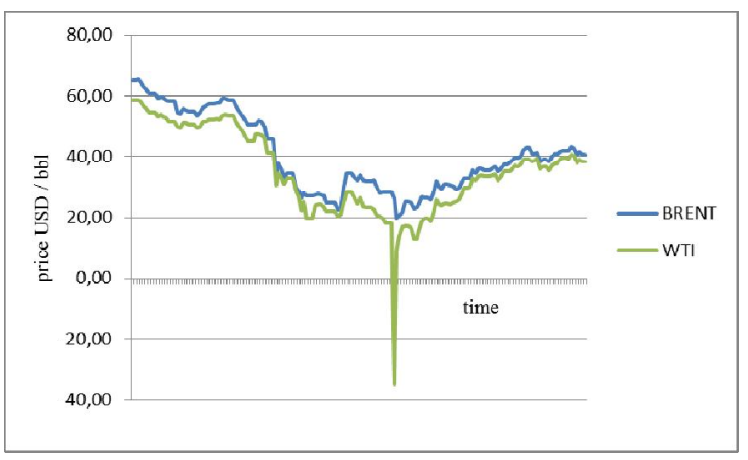

Figure 3: Trends in BRENT and WTI crude oil prices
We can observe the same trend in the dynamics of such data. At the same time, we are observing some differences in the data dynamics being investigated. Therefore, for analysis, we will consider both series of data.

Figure 4 shows the dynamics of prices for natural gas data from the site https://index.minfin.com.ua/markets/gas/). These data are presented in the period 18.01.2020-27.06.2020. We see that the dynamics of natural gas prices is dynamic. At the same time, natural gas price variability is in a small range: 1.5-2 USD / MMBtu. These data are also of interest for the relevant study.

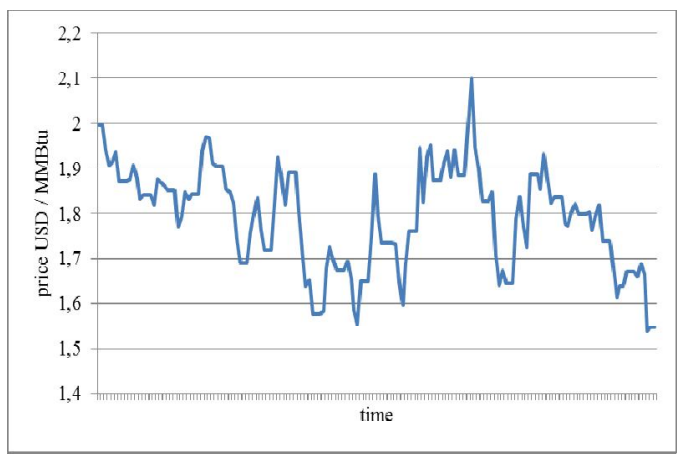

Figure 4: Natural Gas Price Trends

Thus, the data presented are used to determine the corresponding estimates of wavelet coherence. These results are shown below.

\section{RESULTS AND DISCUSSION}

Figure 5 presents the assessment of the wavelet coherence between the data presented in Figure 1 and Figure 3 (oil brand - BRENT).

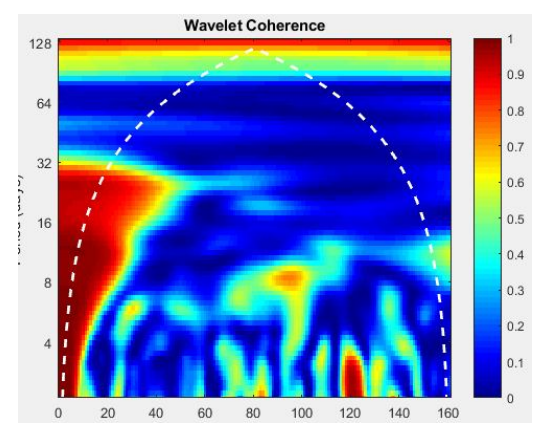

Figure 5: Assessment of wavelet coherence between the data presented in Figure 1 and Figure 3 (oil brand - BRENT)

Figure 6 shows the assessment of the wavelet coherence between the data presented in Figure 1 and Figure 3 (oil brand - WTI). 


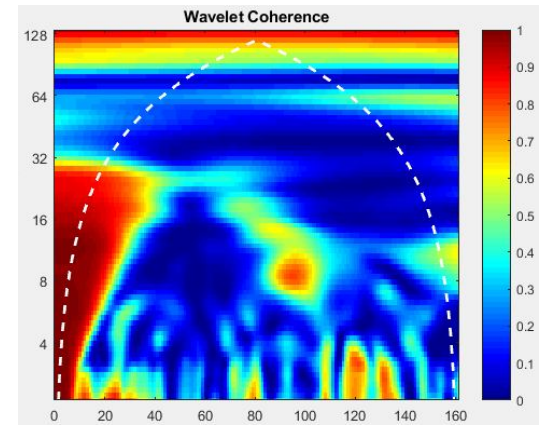

Figure 6: Assessment of wavelet coherence between the data presented in Figure 1 and Figure 3 (oil brand - WTI)

Figure 5 and Figure 6 show (and further for other figures that are presented below):

- dashed white line, which limits the region of reliable values of wavelet coherence with a confidence level of at least 0.95 ; - scale for analyzing the significance of wavelet coherence data. Such data for clarity also have color values. This data displays the corresponding wavelet coherence values in the figure that is shown;

- the axis shows the depth of the relationship between the series of data that are being analyzed;

- the axis shows the ordinal values of the data for the period 18.01.2020-27.06.2020.

The wavelet coherence estimates shown in Figure 5 and Figure 6 are approximately the same. But the data in Figure 6 is more clearly detailed. At the same time, it should be noted that the influence of COVID-19 (for dynamics cumulative total of cases diseased) on the dynamics of oil prices is fragmented. At the same time, such fragmentation is manifested for periods of time up to 4 days (as a rule). A longer effect, associated with the expectation of a possible change in oil prices, was observed in the middle of the studied period of time. But it should be noted that this period was a turning point in the change in oil prices (see data in Figure 3). Such dependence (see data in Figure 5 and Figure 6) manifested itself from 8 to 16 days. These data correlate with the findings of the study [11].

Figure 7 provides an estimate of the wavelet coherence between the data presented in Figure 1 and Figure 4 (dynamics of the price of natural gas).

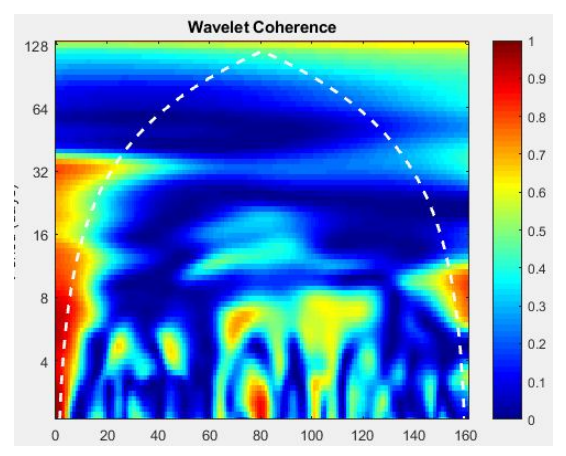

Figure 7: Assessment of wavelet coherence between the data presented in Figure 1 and Figure 4 (dynamics of the price of natural gas)
The data in Figure 7 shows the presence of small and long-term relationships between the data series that are being investigated. In other words, the expectation of a change in the price of natural gas under the influence of the dynamics of the incidence on COVID-19 has both a short and long term. This fact can be taken into account when developing appropriate intelligent systems for production management. However, such expectations are fragmented.

Figure 8 presents the assessment of the wavelet coherence between the data presented in Figure 2 and Figure 3 (oil brand - BRENT).

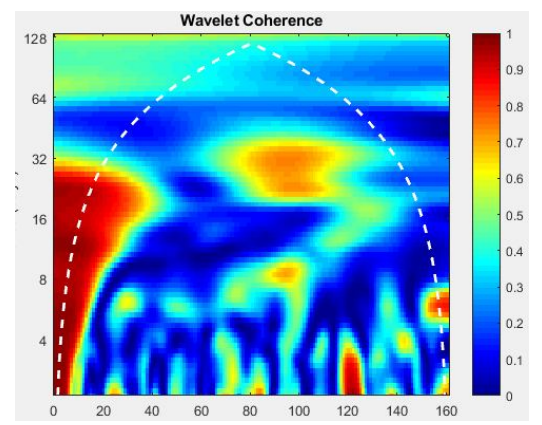

Figure 8: Assessment of wavelet coherence between the data presented in Figure 2 and Figure 3 (oil brand - BRENT)

Figure 9 shows the assessment of the wavelet coherence between the data presented in Figure 2 and Figure 3 (oil brand - WTI).

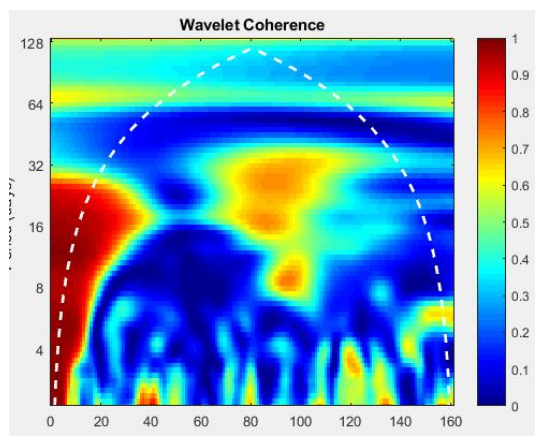

Figure 9: Assessment of wavelet coherence between the data presented in Figure 2 and Figure 3 (oil brand - WTI)

We see that the data in Figure 8 and Figure 9 are approximately the same. These displays the same dynamics for oil prices (see data in Figure 3).

The data in Figure 8 and Figure 9 are also comparable to the data in Figure 5 and Figure 6, respectively. Nevertheless, the data of Figure 8 and Figure 9 are more clearly detailed than the data of Figure 5 and Figure 6. Thus, to analyze the impact of COVID-19 on price dynamics, it is advisable to take into account data of cases diseased in the context of each day from the studied interval. At the same time, for example, in a study [11], an analysis was made for data that reflect the cumulative total of cases diseased. 
Figure 10 presents the assessment of the wavelet coherence between the data presented in Figure 2 and Figure 4 (dynamics of the price of natural gas).

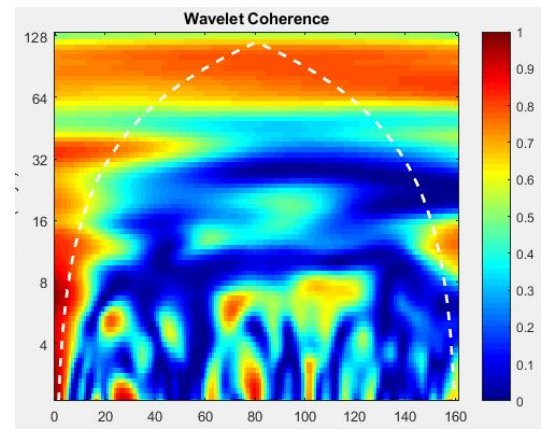

Figure 10: Assessment of wavelet coherence between the data presented in Figure 2 and Figure 4 (dynamics of the price of natural gas)

The data in Figure 10 are more detailed than the data in Figure 7. In particular, we can observe longer-term relationships between the series of data that are being investigated. Moreover, this dependence is characteristic of the middle of the studied time period. As a result, we see that against the background of an increase in the incidence of COVID-19 (see the data in Figure 2), natural gas prices are decreasing (see the data in Figure 4).

Thus, in general, we can talk about the adequacy of the wavelet coherence tool for assessing the impact of COVID-19 on changes in prices for basic energy resources.

\section{CONCLUSION}

Epidemics and pandemics affect all spheres of human activity. This thesis is fully supported by the COVID-19 pandemic, which is currently distributed worldwide. Therefore, it is important to assess the impact of a pandemic on various areas of human activity. A key area of human activity is its economic activity. This allows you to have the resources to overcome the epidemic and further economic development. Among the key concepts for maintaining human economic activity, the dynamics of prices for basic energy resources should be highlighted.

The paper shows the feasibility of using the ideology of wavelets to assess the impact of COVID-19 on the dynamics of prices for basic energy resources. In particular, estimates are given of the impact of COVID-19 on the price of oil and the price of natural gas. It was noted that the assessment of the impact of the dynamics of data of cases diseased in the context of each day from the studied interval on the dynamics of prices for basic energy resources is more informative and has clear detail.

The results can be used to build intelligent systems for managing economic activity.

\section{ACKNOWLEDGEMENTS}

The author (Mohammad Ayaz Ahmad) would like to acknowledge the keen support in financial assistance for this work of the Vice Presidency / Studies and Scientific Research/Deanship of Scientific Research on behalf of University of Tabuk, Kingdom of Saudi Arabia and Ministry of Higher Education, K.S.A under the research grant no. S-0263-1436/dated 15-03-1436 [19]-[27]. And also highly acknowledge the Department of Informatics, Kharkiv National University of RadioElectronics, Ukraine in numerous help and support to complete this article.

\section{REFERENCES}

1. S. T. de Farias, S. Jheeta, S., and F. Prosdocimi. Viruses as a survival strategy in the armory of life, History and philosophy of the life sciences, Vol. 41, no. 4, pp. 41-45, 2019. https://doi.org/10.1007/s40656-019-0287-5

2. A. Ma. Babker, O. I. A. Mohammed, and V. Lyashenko. COVID-19 data based on wavelet coherence estimates for selected countries in the Eastern Mediterranean, World Journal of Advanced Research and Reviews, Vol. 6, no. 3, pp. 110-120, 2020. https://doi.org/10.30574/wjarr.2020.6.3.0188

3. Y. Zhang, J. Wang, and Z. Li. Uncertainty modeling of distributed energy resources: techniques and challenges, Current Sustainable/Renewable Energy Reports, Vol. 6, no. 2, pp. 42-51, 2019. https://doi.org/10.1007/s40518-019-00129-0

4. A. J. Kucharski, and et al. Early dynamics of transmission and control of COVID-19: a mathematical modelling study, The lancet infectious diseases, Vol. 20, no 5, pp. 553-558, 2020. https://doi.org/10.1016/S1473-3099(20)30144-4

5. H. Tian, and et al. An investigation of transmission control measures during the first 50 days of the COVID-19 epidemic in China, Science. Vol. 368, no. 6491, pp. 638-642, 2020.

https://doi.org/10.1126/science.abb6105

6. S. Zhao, and et al. Estimating the Unreported Number of Novel Coronavirus (2019-nCoV) Cases in China in the First Half of January 2020: A Data-Driven Modelling Analysis of the Early Outbreak, Journal of clinical medicine, Vol. 9, no. 2, pp. 388, 2020.

https://doi.org/10.3390/jcm9020388

7. J. T. $\mathrm{Wu}$, and et al. Estimating clinical severity of COVID-19 from the transmission dynamics in Wuhan, China, Nature Medicine, Vol. 26, no. 4, pp. 506-510, 2020.

https://doi.org/10.1038/s41591-020-0822-7

8. S. Zhao, and $\mathrm{H}$. Chen. Modeling the epidemic dynamics and control of COVID-19 outbreak in China, Quantitative Biology, pp. 1-9, 2020. https://doi.org/10.1007/s40484-020-0199-0

9. C. Albulescu. Coronavirus and financial volatility: $\mathbf{4 0}$ days of fasting and fear, arXiv preprint arXiv:2003.04005, 2020. 
10. C. Albulescu. Coronavirus and oil price crash, Available at SSRN 3553452, 2020.

11. A. Sharif, C. Aloui, and L. Yarovaya. COVID-19 pandemic, oil prices, stock market, geopolitical risk and policy uncertainty nexus in the US economy: Fresh evidence from the wavelet-based approach, International Review of Financial Analysis, Vol. 70, pp. 101496, 2020.

https://doi.org/10.1016/j.irfa.2020.101496

12. M. A. Ahmad, S. K. Mustafa, O. Zeleniy O., and V. Lyashenko. Wavelet Coherence as a Tool for Markers Selection in the Diagnosis of Kidney Disease, International Journal of Emerging Trends in Engineering Research, Vol. 8, no. 2, pp. 378-383, 2020. https://doi.org/10.30534/ijeter/2020/23822020

13. A. A. A. Elgadir, A. M. Babker, A. L. Osman, M. Ismail, and V. Lyashenko. New Approach for Analysis the Correlation of Some Oxidative Markers in Type 2 Diabetes Mellitus by Data Wavelet Analysis, Indian Journal of Public Health Research \& Development, Vol. 10, no. 11. pp. 2449-2455, 2019. https://doi.org/10.5958/0976-5506.2019.03975.5

14. M. Ayaz, I. Tvoroshenko, J. H. Baker, and V. Lyashenko. Computational Complexity of the Accessory Function Setting Mechanism in Fuzzy Intellectual Systems, International Journal of Advanced Trends in Computer Science and Engineering, Vol. 8, no. 5, pp. 2370-2377, 2019. https://doi.org/10.30534/ijatcse/2019/ 77852019

15. G. Chetverikov, O. Puzik, and I. Vechirska. Multiple-valued structures of intellectual systems, In 2016 XIth International Scientific and Technical Conference Computer Sciences and Information Technologies (CSIT), pp. 204-207, 2016. https://doi.org/10.1109/STC-CSIT.2016.7589907

16. G. Chetverikov, I. Vechirska, and S. Tanyanskiy. The methods of algebra of finite predicates in the intellectual system of complex calculations of telecommunication companies, In 2014 24th International Crimean Conference Microwave \& Telecommunication Technology, pp. 346-347, 2014. https://doi.org/10.1109/CRMICO.2014.6959425

17. C. Torrence, and P. J. Webster. Interdecadal changes in the ENSO-monsoon system, Journal of Climate, Vol. 12 , no. 8, pp. 2679-2690, 1999.

https://doi.org/10.1175/1520-0442(1999)012<2679:ICI $\mathrm{TEM}>2.0 . \mathrm{CO} ; 2$

18. A. Grinsted, J. C. Moore, and S. Jevrejeva. Application of the cross wavelet transform and wavelet coherence to geophysical time series, Nonlinear processes in geophysics, Vol. 11, no. 5/6, pp. 561-566, 2004.

19. M. Ayaz, I. Tvoroshenko, J. H. Baker, and V. Lyashenko. Modeling the Structure of Intellectual Means of Decision-Making Using a System-Oriented NFO Approach, International Journal of Emerging Trends in Engineering Research, Vol. 7, no. 11, pp. 460-465, 2019. https://doi.org/10.30534/ijeter/2019/107112019

20. Vyacheslav Lyashenko, Syed Khalid Mustafa, Svitlana Sotnik, M. Ayaz Ahmad. Basic Principles of Decision Making upon Receipt of New Nanomaterial,
International Journal of Advanced Trends in Computer Science and Engineering (IJATCSE), Vol. 8, no. 5, (2019), pp. 2680-2685.

https://doi.org/10.30534/ijatcse/2019/124852019

21. Vyacheslav Lyashenko, Syed Khalid Mustafa, Nataliya Belova, M. Ayaz Ahmad. Some Features in Calculation of Mold Details for Plastic Products, International Journal of Emerging Trends in Engineering Research (IJETER), Vol. 7, no. 11, (2019), pp. 720-724. https://doi.org/10.30534/ijeter/2019/517112019

22. Vyacheslav Lyashenko, Syed Khalid Mustafa, Irina Tvoroshenko, M. Ayaz Ahmad. Methods of Using Fuzzy Interval Logic During Processing of Space States of Complex Biophysical Objects, International Journal of Emerging Trends in Engineering Research (IJETER), Vol. 8, no. 2, (2020), pp. 372-377. https://doi.org/10.30534/ijeter/2020/22822020

23. M. Ayaz Ahmad, Syed Khalid Mustafa, Oleksandr Zeleniy, Vyacheslav Lyashenko. Wavelet Coherence as a Tool for Markers Selection in the Diagnosis of Kidney Disease, International Journal of Emerging Trends in Engineering Research (IJETER), Vol. 8, no. 2, (2020), pp. 378-383. https://doi.org/10.30534/ijeter/2020/23822020

24. Irina Tvoroshenko, M. Ayaz Ahmad, Syed Khalid Mustafa, Vyacheslav Lyashenko, Adel R. Alharbi. Modification of Models Intensive Development Ontologies by Fuzzy Logic, International Journal of Emerging Trends in Engineering Research (IJETER), Vol. 8, no. 3 (2020), pp. 939-944.

https://doi.org/10.30534/ijeter/2020/50832020

25. Svitlana Sotnik, Syed Khalid Mustafa, M. Ayaz Ahmad, Vyacheslav Lyashenko, Oleksandr Zeleniy. Some Features of Route Planning as the Basis in a Mobile Robot, International Journal of Emerging Trends in Engineering Research (IJETER), Vol. 8, no. 5 (2020), pp. 2074-2079. https://doi.org/10.30534/ijeter/2020/97852020

26. M. Ayaz, T. Sinelnikova, S. K. Mustafa, and V. Lyashenko. Features of the Construction and Control of the Navigation System of a Mobile Robot, International Journal of Emerging Trends in Engineering Research, Vol. 8, no. 4, pp. 1445-1449, 2020. https://doi.org/10.30534/ijeter/2020/82842020

27. M. Ayaz, I. Tvoroshenko, J. H. Baker, and V. Lyashenko. Computational Complexity of the Accessory Function Setting Mechanism in Fuzzy Intellectual Systems, International Journal of Advanced Trends in Computer Science and Engineering, Vol. 8, no. 5, pp. 2370-2377, 2019.

https://doi.org/10.30534/ijatcse/2019/ 77852019 